\title{
Medio-lateral entry pin versus lateral entry pin for displaced pediatric supracondylar fractures: A comparative, prospective study
}

\author{
Manoj Kandel, Hemant Kumar Gupta, Rajkumar Ravi Hamal, Amit Ranjan Mishra, Rahul \\ Shrestha, Abhisek Ranjan, Robin Shrestha \\ Department of Orthopedics, College of Medical Sciences Bharatpur, Nepal
}

Correspondence
Dr. Manoj Kandel
Department of Orthopedics
Bharatpur Government Hospital
Bharatpur, Chitwan
Email:
manojkandel17@gmail.com

DOI: http://dx.doi.org/10.3126/ jcmsn.v11i4.14322

\begin{abstract}
Background \& Objectives: Supracondylar fracture is one of the commonest fractures in children. Although the technique of pinning is controversial, percutaneous medio-lateral entry pinning is theoretically considered more stable biomechanical construct. The drawback of this method is injury to ulnar nerve which is not encountered in only lateral entry pinning. Materials \& Methods: This was a prospective, comparative and observational study done in 60 patients which was alternately divided into two groups. The first group (A) underwent medio-lateral entry pinning and the second group (B) underwent lateral entry pinning. They were followed for 24 weeks and the outcome was assessed using Flynn's criteria. Results: At twenty-four weeks, the mean loss of range of motion of elbow in medio-lateral pinning group was 3.70 degrees $(\mathrm{SD} \pm 1.93)$ and that in lateral pinning group was 4.23 degrees $(\mathrm{SD} \pm 1.38)$. The mean loss in carrying angle at twenty-four weeks in medio-lateral group was 2.93 degrees $(\mathrm{SD} \pm 2.19)$ and that in lateral group was $4.17(\mathrm{SD} \pm 2.24)$. There were $2(6.67 \%)$ cases of iatrogenic ulnar nerve injury in medio-lateral pinning group. Out of thirty patients, in medio-lateral pinning group, 25 had excellent results, 5 had good results and none had fair or poor results. While out of 30 patients in lateral pinning group, 23 had excellent results, 7 had good results and none had fair or poor results. Conclusion: There is no significant difference in outcome in terms of loss of carrying angle and range of motion between the medio-lateral pinning group and the lateral pinning group at the end of 6 months.

Key words: Flynn's criteria, Percutaneous pinning, Supracondylar fracture
\end{abstract}

Citation: Kandel M, Gupta HK, Hamal RR, Mishra AR, Shrestha R, Ranjan A, et al. Medio-lateral entry pin versus lateral entry pin for displaced pediatric supracondylar fractures: A comparative, prospective study. JCMS Nepal. 2015;11(4):28-31.

\section{INTRODUCTION}

Supracondylar fracture is the most common type of elbow fracture in children aged between 5 and 7 years and accounting for $3 \%$ of all pediatric fractures. Several concepts have emerged in the past decade regarding the management and though debate persists in methods of treating displaced supracondylar fractures the goals of treatment are to provide anatomic reduction, stability, and prevent postoperative deformity including cubitus varus. Currently, the standard of care for most type II fractures and all type III fractures involves closed reduction with percutaneous pin fixation. ${ }^{1}$ Swenson first described a method of percutaneous Kirschner wire transfixation of supracondylar fractures in children. $^{2}$

Medio-lateral pinning has been shown to have greatest biomechanical stability than lateral parallel or divergent pinning. Because of the documented iatrogenic ulnar nerve injury from the medio-lateral entry pin with prevalence rate up to $12 \%$, there has been a predilection for placement of lateral entry pins. $^{3,4}$

This study was conducted to assess the cosmetic and functional outcome as well as complications of each method.

\section{MATERIALS AND METHODS}

This study was a prospective comparative observational study done in 60 patients divided into two equal groups. Group A was assigned to the patients who underwent medio-lateral entry pinning and Group $B$ assigned to the patients who underwent lateral entry pinning. The patients who 
were admitted underwent alternate pinning technique. This study was carried out in College of Medical Sciences - Teaching Hospital (COMS-TH) Bharatpur, Chitwan from January 2012 to December 2013. All supracondylar fractures Gartland Type II and IIIA and IIIB below the age of 12 years were included in the study. The exclusion criteria included, Gartland Type I fractures, open fractures and fractures associated with vascular injuries and compartment syndrome.

All the patients admitted either from emergency department or outpatient department was operated alternately by lateral and medio-lateral pining methods. General anesthesia was used for all cases and fractures were reduced by closed method. Traction to the fractured limb with elbow in 20 degree flexion with counter traction at arm was applied. After gradual correction of rotation and medio-lateral shift the elbow was flexed with pressure on olecranon to correct posterior shift. Pronation of forearm and hyperflexion done and reduction was checked on C-arm in anteroposterior, lateral and two oblique planes. Two to three Kirschner wires was then inserted from the lateral side or from both sides. Fracture stability was assessed on image intensifier by screening the fracture under varus/valgus, flexion/extension and rotational stresses. The wires were then bent and cut outside the skin, well padded and the limb immobilized in an above-elbow slab with the elbow at sixty to ninety degrees. Patients were discharged within 24 hours to 48 hours of surgery.

All the patients were followed up at the orthopedic out-patient department for minimal of six months at interval of 1 week, 4 weeks, 12 weeks and 24 weeks. On follow ups, patient were examined clinically for any complications like pin tract infections, pin migration, deformity, range of motion and radiologically for fracture union. The $\mathrm{k}$ wires and posterior slabs were removed at the end of 4th week. Flynn's grading was used to assess the result in all cases. ${ }^{5}$

The details of each patient and the values of each variable were filled up in Statistical Package for the
Table 1: Flynn's Grading

\begin{tabular}{ccc} 
Grading & $\begin{array}{c}\text { Cosmetic Factor: } \\
\text { Carrying Angle } \\
\text { Loss (Degrees) }\end{array}$ & $\begin{array}{c}\text { Functional Factor: } \\
\text { Motion Loss } \\
\text { (Degrees) }\end{array}$ \\
\hline Excellent & $0-5^{\circ}$ & $0-5^{\circ}$ \\
\hline Good & $6-10^{\circ}$ & $6-10^{\circ}$ \\
\hline Fair & $11-15^{\circ}$ & $11-15^{\circ}$ \\
Poor & $>15^{\circ}$ & $>15^{\circ}$
\end{tabular}

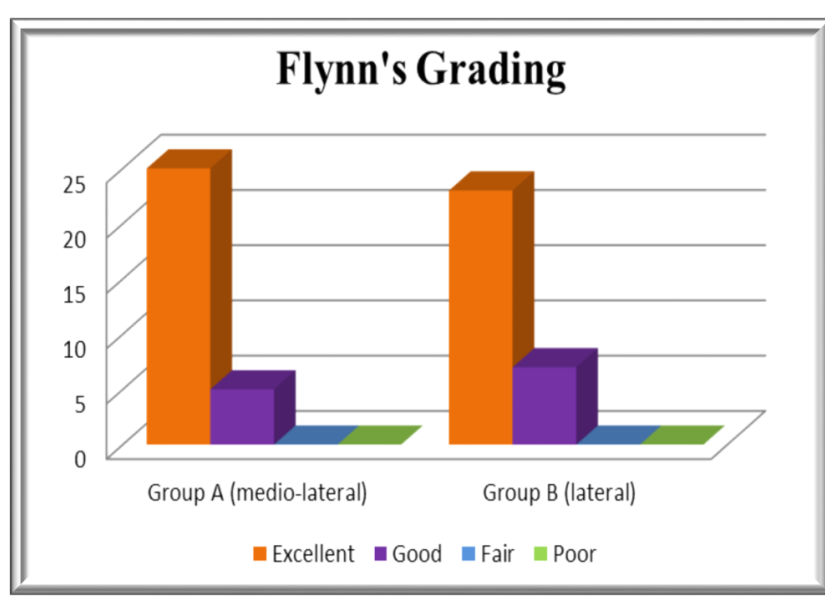

Fig 1: Flynn's Grading

Social Sciences (SPSS) software version 22. After the data of all sixty patients were filled up, the mean, standard deviation and $p$ value of different variables were calculated.

\section{RESULT}

A total of 60 patients were operated out of which there were 41 boys and 19 girls. Thirty patients underwent medio-lateral pinning and another thirty underwent lateral pinning. The mean ages of the patients who were allocated in medio-lateral pinning group was 7.6 years $(\mathrm{SD} \pm 2.8)$ and the lateral pinning group was also 8.2 years $(\mathrm{SD} \pm 3.5)$. Out of sixty patients, left side was injured in 22 patients and the right side was involved in 28 patients. The duration from injury to time of operation ranged from $0-6$ days, with a mean of 1.3 days.

Table 2: Loss of range of motion and carrying angle

\begin{tabular}{cccccc} 
& & Range of motion loss & p value & $\begin{array}{c}\text { Mean carrying } \\
\text { angle loss }\end{array}$ & $\mathrm{p}$ value \\
\multirow{2}{*}{$24^{\text {th }}$ week } & $\begin{array}{c}\text { Lateral pinning } \\
\text { group }\end{array}$ & $\begin{array}{c}4.23 \text { degrees (SD } \\
\pm 1.38)\end{array}$ & & $4.17(\mathrm{SD} \pm 2.24)$ & \\
& $\begin{array}{c}\text { Medio-lateral } \\
\text { pinning group }\end{array}$ & $\begin{array}{c}3.70 \text { degrees } \\
(\mathrm{SD} \pm 1.93)\end{array}$ & 0.042 & $\begin{array}{c}2.93 \text { degrees } \\
(\mathrm{SD} \pm 2.19)\end{array}$ & 0.103 \\
\hline
\end{tabular}



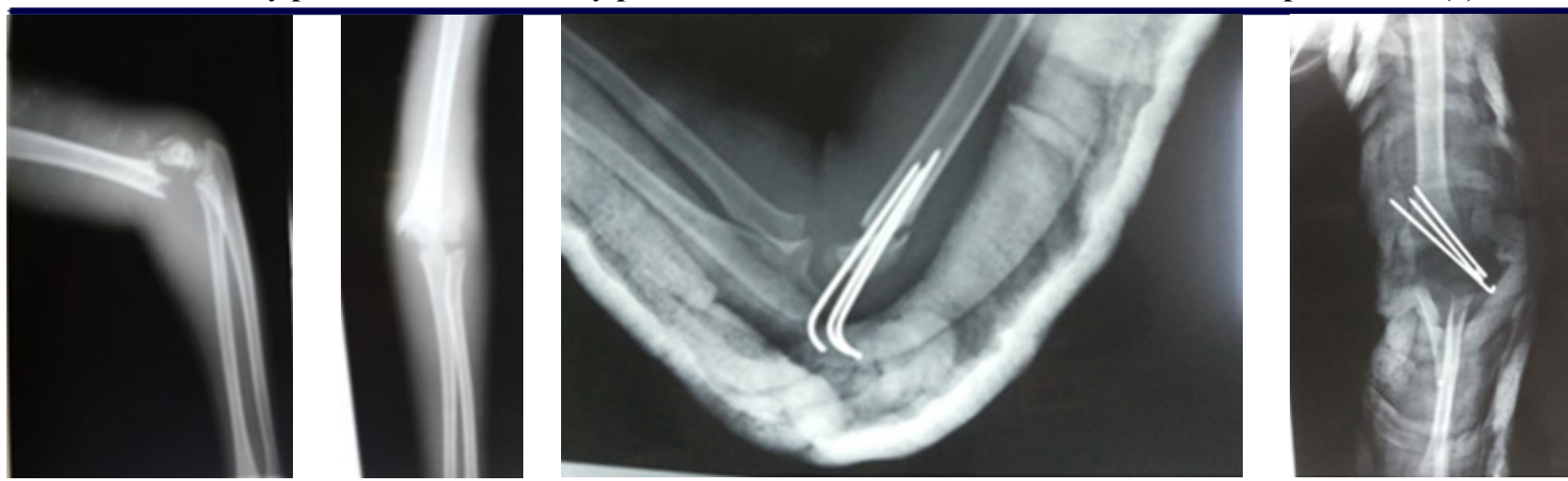

Fig 2: Pre-op and post-op x-rays of lateral pinning
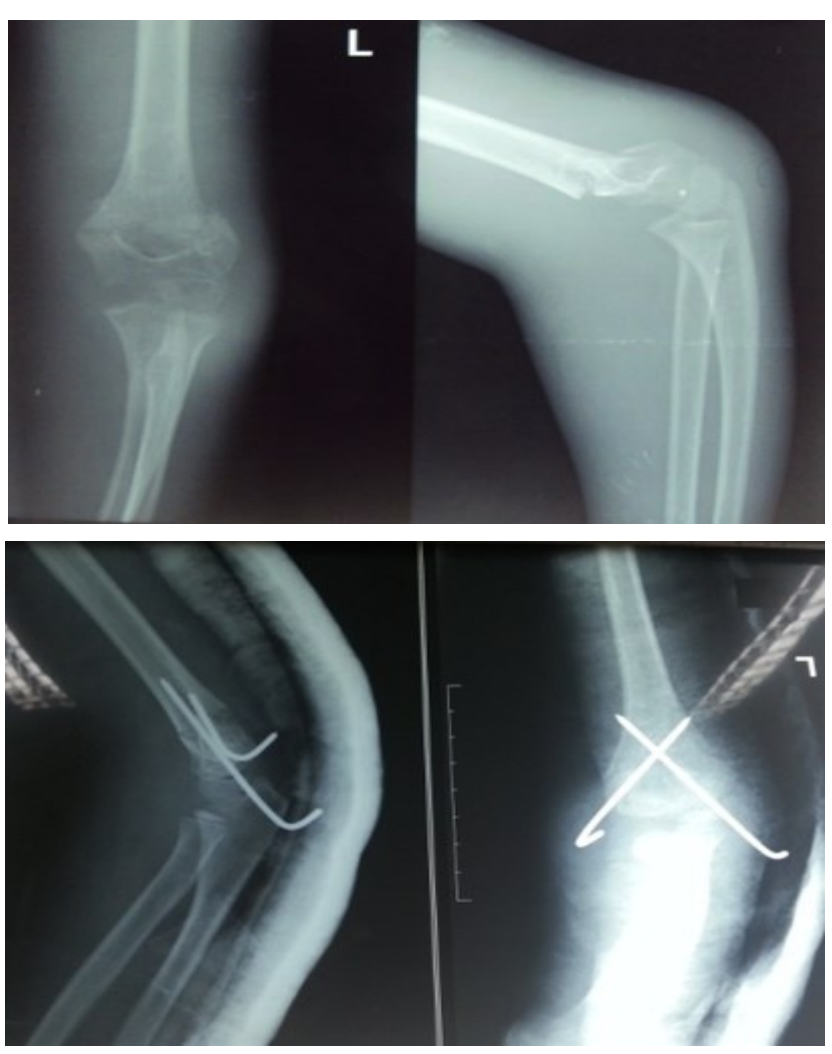

Fig 3: Pre-op and post-op x-rays of mediolateral pinning

Out of thirty patients, in medio-lateral pinning group, 25 had excellent results, 5 had good results and none had fair or poor results. While out of 30 patients in lateral pinning group, 23 had excellent results, 7 had good results and none had fair or poor results. None required re-manipulation, all fractures united well and only $2(6.67 \%)$ cases of ulnar nerve injury were encountered in medio-lateral pinning group.

\section{DISCUSSION}

There is no consensus regarding the ideal method of treatment of supracondylar fractures in children. Several treatment modalities of treatment have been recommended. Closed reduction and percutaneous pinning is the most popular treatment of pediatric

supracondylar fractures of the humerus. ${ }^{6-8}$ Many studies showed that lateral pinning gives sufficient biomechanically stability without injuring ulnar nerve. ${ }^{9-11}$ Similarly injury to the ulnar nerve was encountered when medio-lateral pinning were attempted. ${ }^{12-14}$

When we compare our findings of iatrogenic ulnar nerve injury in 2 patients of group A, with none in group $\mathrm{B}$, we find that the most frequent problem faced while performing medial pinning is iatrogenic ulnar nerve injury. Both cases of iatrogenic ulnar nerve injury did not recover within our study period. In our study, 7 patients (15.6\%) developed minor pin tract infection, 5 in medio-lateral entry pinning and 2 in lateral entry pinning. All cases of infection were managed with oral antibiotics and regular pin site dressing.

Various comparative studies have concluded that there are no statistical differences in cosmetic and functional outcome in fractures treated by either method. $^{15,16}$

\section{CONCLUSION}

The conclusion of this study is that there is no significant difference in outcome in terms of loss of carrying angle and range of motion between the medio-lateral pinning group and the lateral pinning group although lateral entry pinning ensures safety of ulnar nerve.

\section{REFERENCES}

1. Abzug JM, Herman MJ. Management of supracondylar humerus fractures in children: current concepts. J Am Acad Orthop Surg. 2012;20(2):69-77. DOI:10.5435/ JAAOS-20-02-069; PMID:22302444.

2. Swenson AL. The treatment of supracondylar fractures of the humerus by Kirschner-wire transfixion. J Bone Joint Surg. 1948;30(4):993-7.

3. Skaggs DL, Hale JM, Bassett J, Kaminsky C, Ray RM, Tolo VT. Operative treatment of supracondylar fractures of the humerus in children. The consequences of pin placement. J Bone Joint Surg Am. 2001;83-A(5):735-40. PMID:11379744. 
4. Gaston RG, Cates TB, Devito D, Schmitz M, Schrader T, Busch M, et al. Medial and lateral pin versus lateral-entry pin fixation for type 3 supracondylar fractures in children: a prospective, surgeon-randomized study. J Pediatr Orthop. 2010;30(8):799-806. DOI:10.1097/ BPO.0b013e3181f73d59; PMID:21102204.

5. Flynn JC, Mathews JG, Benoit RL. Blind pinning of displaced supracondylar fractures of the humerus in children. J Bone Joint Surg Am. 1974; 56(2): 263-73 PMID:4375679.

6. Sibinski M, Sharma H, Sherlock DA. Lateral versus medio-lateral wire fixation for displaced extension supracondylar humeral fractures in children. Injury. 2006;37(10):961-5.

DOI:10.1016/j.injury.2006.02.054; PMID:16765353.

7. Khan AQ, Goel S, Abbas M, Sherwani MK. Percutaneous Kwiring for Gartland type III supracondylar humerus fractures in children. Saudi Med J. 2007;28 (4):603-6. PMID: 17457486.

8. Tripuraneni KR, Bosch PP, Schwend RM, Yaste JJ. Prospective, surgeon randomized evaluation of mediolateraled pins versus lateral pins for unstable supracondylar humerus fractures in children. J Pediatr $\begin{array}{lll}\text { Orthop B. 2009;18(2):93-8. } & \text { B. }\end{array}$ DOI:10.1097/BPB.0b013e32832989ff; PMID:19276994.

9. Gordon JE, Patton CM, Luhmann SJ, Bassett GS, Schoenecker PL. Fracture stability after pinning of displaced supracondylar distal humerus fractures inchildren. J Pediatr Orthop. 2001;21(3):313-8. DOI:10.1097/00004694-200105000-00010; 10.1097/01241398-200105000-00010.

10. Gupta H, Khare K, Chaurasia D. Results of lateral pin fixation for the displaced supracondylar fracture of humerus in children. JCMS-Nepal. 2012;8(1):13-7. DOI: $10.3126 /$ jcmsn.v8i1.6820.

11. Brauer CA, Lee BM, Bae DS, Waters PM, Kocher MS. A systematic review of medial and lateral entry pinning versus lateral entry pinning for supracondylar fractures of the humerus. Journal of Pediatric Orthopaedics. 2007;27 (2):181-6. DOI:10.1097/bpo.0b013e3180316cf1; PMID:17314643.

12. Topping RE, Blanco JS, Davis TJ. Clinical evaluation of medio-lateraled-pin versus lateral-pin fixation in displaced supracondylar humerus fractures. Journal of Pediatric Orthopaedics. 1995;15(4):435-9. DOI:10.1097/01241398-199507000-00004;

PMID:7560029.

13. Edmonds EW, Roocroft JH, Mubarak SJ. Treatment of displaced pediatric supracondylar humerus fracture patterns requiring medial fixation: a reliable and safer medio-lateral-pinning technique. Journal of Pediatric Orthopaedics. 2012;32(4):346-51. DOI:10.1097/BPO.0b013e318255e3b1; PMID:22584833.

14. Guy SP, Ponnuru RR, Gella S, Tulwa N. Lateral Entry Fixation Using Three Divergent Pins for Displaced Paediatric Supracondylar Humeral Fractures. International Scholarly Research Notices. 2011;2011:5. DOI:10.5402/2011/137372.

15. Wilson PD. Fractures and dislocations in the region of the elbow. Surg Gynecol Obstet. 1933;56:335-59.

16. Yen Y-M, Kocher MS. Lateral entry compared with medial and lateral entry pin fixation for completely displaced supracondylar humeral fractures in children. J Bone Joint Surg Am. 2008;90(Supplement 2 Part 1):2030. DOI: 10.2106/jbjs.g.01337. 